\title{
Reduced neonatal lung function and wheezing illnesses during the first 5 years of life
}

\author{
Anne C. van der Gugten ${ }^{1}$, Cuno S.P.M. Uiterwaal², Nienke van Putte-Katier', \\ Marije Koopman ${ }^{1}$, Theo J.M. Verheij ${ }^{2}$ and Cornelis K. van der Ent ${ }^{1}$
}

Affiliations: 'Dept of Paediatric Pulmonology, Wilhelmina Children's Hospital, University Medical Centre Utrecht, Utrecht, and ${ }^{2}$ Julius Center for Health Sciences and Primary Care, University Medical Center Utrecht, Utrecht, the Netherlands.

Correspondence: A.C. van der Gugten, Wilhelmina Children's Hospital/University Medical Center Utrecht, Dept of Paediatric Pulmonology, Room KH.01.419.0, PO Box 85090, 3508 AB Utrecht, the Netherlands. E-mail: a.c.vandergugtendumcutrecht.nl

ABSTRACT Studies of reduced neonatal lung function and wheezing illnesses during childhood show conflicting results. The aim of our study was to assess the association between resistance (Rrs) and compliance $(\mathrm{Crs})$ of the respiratory system by using the single occlusion technique (SOT) and prospectively collected wheezing illnesses during the first 5 years of life in a large birth cohort.

SOT was performed during natural sleep before the age of 2 months. Information about wheezing illnesses was collected from the electronic patient file.

549 infants had a successful SOT measurement and complete medical records. Every $\mathrm{kPa} \cdot \mathrm{L}^{-1} \cdot \mathrm{s}^{-1}$ increase in Rrs was associated with $10 \%$ more consultations in the first 3 years of life. Every $10 \mathrm{~mL} \cdot \mathrm{kPa}^{-1}$ increase in Crs was associated with a $14 \%$ reduction in consultations in the first 3 years of life, $27 \%$ in the fourth to fifth years of life, and a lower probability of having asthma at the age of 5 years (OR 0.66). Children with lateonset or persistent wheezing had significant lower Crs values than their peers.

An increased neonatal resistance is associated with more wheezing illnesses during infancy, while a reduced neonatal compliance is associated with more wheezing illnesses during the first 5 years of life, a late-onset or persistent wheezing phenotype, and asthma.

@ERSpublications

Increased neonatal resistance and reduced neonatal compliance are both associated with more wheezing illnesses http://ow.ly/l3L9i

This article has supplementary material available from www.erj.ersjournals.com

Received: Dec 072011 | Accepted after revision: May 032012 | First published online: Nov 082012

Support statement: The WHISTLER study is supported by grants from the Netherlands Organization for Health Research and Development (ZON-MW), by the University Medical Center Utrecht and by an unrestricted research grant from GlaxoSmithKline, the Netherlands. The funding agencies did not have any role in study design, data collection, analysis and interpretation of data and the writing of this article and the decision to submit it for publication. All researchers are independent from funders.

Conflict of interest: Disclosures can be found alongside the online version of this article at www.erj.ersjournals.com

Copyright @ERS 2013 


\section{Introduction}

Several groups studied the association between neonatal lung function and wheezing symptoms in infancy or in childhood. Although most of these studies concluded that lower early lung and airway function were associated with subsequent development of infant wheezing [1-5], the association between neonatal lung function and wheezing symptoms and asthma in childhood is not consistently found [6-9]. One possible explanation for the inconsistent findings could be that because of the difficulties in measuring infant lung function, most studies had a small sample size. Another issue is that most studies used a single end-point or collected data on symptoms at different ages in a retrospective way. The patterns of symptoms at different ages are associated with a different future risk for asthma $[6,10,11]$. These so-called wheezing phenotypes might also have different underlying pathological mechanisms. Therefore, the association between infant lung function and outcome could differ between wheezing phenotypes or wheezing symptoms at different moments in childhood. To gain more insight into the aetiology, it is important to follow-up a large sample of children longitudinally. In the Wheezing Illnesses Study Leidsche Rijn (WHISTLER) project, we used the single occlusion technique, an easy and noninvasive lung function technique, and were therefore able to measure a large group of infants. All children were closely monitored for all consultations, prescriptions and referrals for wheezing illnesses.

The aim of this study is to analyse the association between standardised neonatal lung function measurements (passive mechanics, resistance (Rrs) and compliance (Crs) of the respiratory system) and the number of prospectively collected general practitioner consultations for wheezing illnesses during the first 5 years of life, different wheezing phenotypes and the presence of asthma.

\section{Methods and materials Study population}

All infants were participants of the WHISTLER project, an ongoing population-based, prospective birth cohort on determinants of wheezing illnesses in children [12], which started in December 2001. Exclusion criteria are gestational age $<36$ weeks, major congenital abnormalities and neonatal respiratory disease. Parents of newborns were asked to participate and, at the age of 3-8 weeks, a lung function measurement was performed. Information about pre- and post-natal risk factors and about the health status of the parents was obtained by questionnaires. During total follow-up, information on primary care consultations and prescriptions for respiratory symptoms was collected. At the age of 5 years, children were invited for a second visit, in which lung function measurements were performed. The medical ethical committee of the University Medical Center Utrecht (Utrecht, the Netherlands) approved the study (project approval number 01/176) and all parents gave written informed consent.

\section{Lung function measurement}

Lung function was performed in healthy neonates before the age of 2 months during natural sleep. The Rrs, Crs and time constant of the total respiratory system $\left(\tau_{\mathrm{rs}}\right)$ were measured in the absence of respiratory muscle activity using the single occlusion technique (SOT) [13-15]. Airflow was measured using a heated Lilly-type pneumotachometer (series 8300 , linear range $0-10 \mathrm{~L} \cdot \mathrm{min}^{-1}$; Hans Rudolph Inc., Kansas City, MO, USA) connected to a face mask (infant mask, size neonate; Hans Rudolph Inc.). To minimise air leakage, the face mask was sealed to the infant's face using therapeutic silicon putty (Thera flex, resistive hand exerciser; Depco Inc., New York, NY, USA). Pressure changes at the airway opening were measured using a pressure transducer (Honeywell, type 163PC01D75; Morristown, NJ, USA). Volume was measured by electronic integration of the airflow signal. To calibrate flow and volume measurement, before every measurement a $100-\mathrm{mL}$ precision syringe (Viasys Healthcare, Höchberg, Germany) was used.

Lung function data were calculated offline using a custom-built software package (Luna 1.6, Utrecht, the Netherlands). Occlusions were accepted or disregarded using the criteria of the European Respiratory Society (ERS)/American Thoracic Society (ATS) Task Force on Infant Lung Function [14, 16]. At least three technically acceptable occlusions were used to calculate mean $\operatorname{Crs}$, Rrs and $\tau_{\mathrm{rs}}$.

At the age of 5 years, children were invited for a second visit in which information about respiratory symptoms during the previous years were assessed by a questionnaire. Forced flow volume manoeuvres were obtained using a heated Lilly head pneumotachometer system (Viasys Healthcare). Measurements were body temperature, pressure and saturation (BTPS) corrected and conformed to the latest ERS/ATS statement for lung function measurements in preschoolers [17]. At least two reproducible flow-volume curves were obtained. The largest forced expiratory volume in $1 \mathrm{~s}$ (FEV1) was selected. 


\section{Definitions of outcome and exposures}

Data on primary care visits and prescriptions were obtained from the general practitioners' electronic patient files. There is standardisation in primary care, as all general practitioners use the International Classification of Primary Care (ICPC) for every consultation [18]. Physician-diagnosed wheeze was assessed using different categories of wheezing illnesses. Medication was classified according to the Anatomical Therapeutical Chemical classification.

\section{Definition of asthma}

Asthma was defined in the following two ways. 1) As at least two consultations, or prescriptions of asthma medication (oral or inhalation corticosteroids, inhalation $\beta$-agonists, leukotriene receptor antagonists) or referrals to a hospital for wheezing illnesses in the fourth to fifth years of life. In our opinion, a single consultation or prescription could be an incidental event; therefore, we defined asthma as at least two consultations, or prescriptions or referrals for wheezing illnesses. 2) A history of asthma (two or three of the following: history of dyspnoea, chest tightness or wheezing, doctor's diagnosis of asthma and/or reported use of asthma medication) and at least one of the following: symptoms in the past 12 months, use of asthma medication in the past 12 months, or a $\mathrm{FEV} 1<10$ th percentile $[9,19]$.

\section{Definition of wheezing phenotypes}

Nonwheezers had no wheezing illnesses during the first 5 years of life; transient wheezers had wheezing illnesses during the first 3 years of life, but not thereafter; late-onset wheezers had no wheezing during the first 3 years of life but did have wheezing illnesses in the fourth to fifth years of life; and persistent wheezers had wheezing illnesses during the first to third years of life and during the fourth to fifth years of life. Wheezing illnesses in these phenotypes are defined as at least two consultations and/or prescriptions for wheezing.

\section{Definitions of exposures}

A positive history of parental allergy, included parental reported allergy to pollen, house dustmite, pets or food. Active maternal smoking during pregnancy was considered present if the mother smoked at least one cigarette per day during pregnancy. Maternal smoke exposure during pregnancy was considered present if the mother smoked actively and/or was exposed to tobacco smoke for $>2 \mathrm{~h}$ per week during pregnancy. Maternal higher education was defined as higher vocational or university education.

\section{Statistical analysis}

$C_{\mathrm{rs}}$ and Rrs were standardised according to age, length, weight at measurement and sex, as these are determinants of lung function. Missing values in length and weight (9\%) were imputed by mean values. Crs and Rrs were non-normally distributed and, therefore, median values and interquartile ranges were provided. Median values for the lung function parameters were compared between children with different phenotypes by Kruskal-Wallis test. The number of consultations was used as a count type outcome, best fitting a Poisson distribution [20]. Poisson regression was used to assess the association between Crs and Rrs and the number of primary care consultations for wheezing illnesses in the first 3 years of life and in the fourth and fifth years of life. Logistic regression analysis was used to study the association between Crs and Rrs and asthma at the age of 5 years. The association between SOT and spirometry at the age of 5 years was studied by linear regression analysis. The models were adjusted for maternal smoke exposure during pregnancy, parental allergy and the presence of siblings, because these variables may be associated with lung function and wheezing illnesses. Because we have previously showed that daycare visits, ethnicity and maternal age $>30$ years are determinants of consultations for respiratory illnesses [21], we also adjusted the regression analyses with consultations or asthma as outcome for these potential confounders, additionally to the above-mentioned variables. The linear regression model was additionally adjusted for length and weight at the spirometry measurement.

Results are presented as odds ratios, regression coefficients, 95\% confidence intervals, p-values and incidence rate ratios, indicating relative change in outcome rates [20]. Associations were considered statistically significant if $\mathrm{p}<0.05$. All analyses were run using SPSS (version 15.0, SPSS Inc., Chicago, IL, USA).

\section{Results}

\section{Subject characteristics}

An overview of the recruitment and inclusion of infants in the ongoing WHISTLER project is given in figure 1. Among the subjects aged 5 years, valid neonatal lung function measurements were obtained in $77 \% .549$ infants had successful neonatal lung function measurement and complete medical records for the 


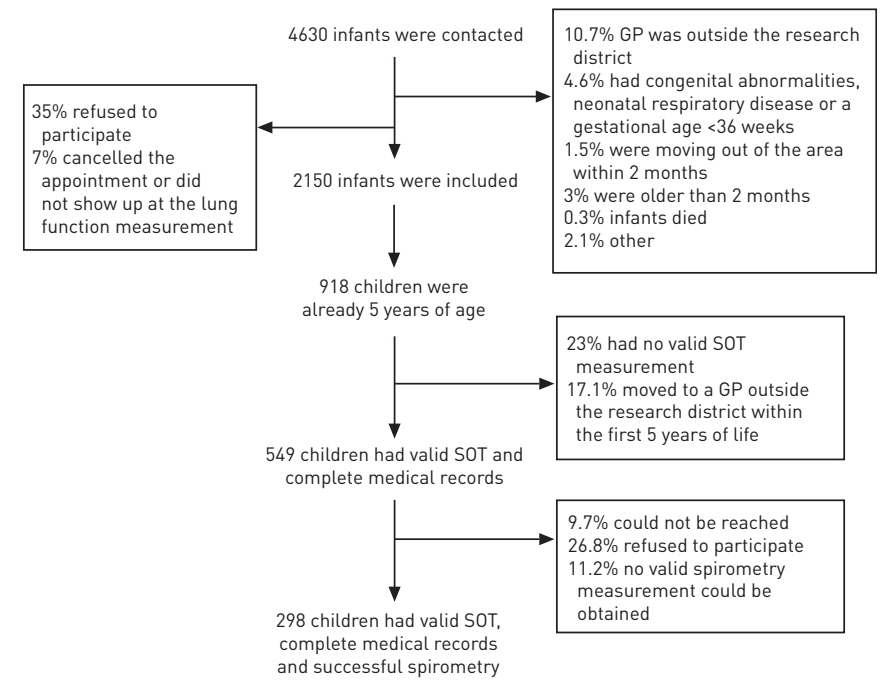

FIGURE 1 Overview of the recruitment and inclusion of infants in the Wheezing Illnesses Study Leidsche Rijn (WHISTLER) project. GP: general practitioner; SOT: single occlusion technique.

first 5 years of life. Among these children, 53 could not be reached when they were 5 years of age. Among the remaining 496 children, 349 (70\%) children agreed to participate in the follow-up study. Valid followup lung function measurements at 5 years of age were obtained in 298 children $(85 \%$, mean \pm SD age $5.4 \pm 0.25$ years). Mean \pm sd FEV1 at the age of 5 years was $1.26 \pm 0.185 \mathrm{~L}$ and forced expiratory flow at 25$75 \%$ of forced vital capacity $(\mathrm{FEF} 25-75 \%)$ was $1.52 \pm 0.415 \mathrm{~L}$.

The different subgroups of children already aged 5 years were slightly younger at the lung function measurement than the average total cohort, had a lower $C_{r s}$ and a higher Rrs, and their mothers were more often exposed to smoke during pregnancy (table 1). An extended version of table 1 with statistics of the different subgroups compared with the total cohort is shown in table S1.

TABLE 1 General characteristics of the various study populations

Total cohort Group that already reached 5 years

\section{Group with successful SOT and complete medical records}

Group with successful SOT, complete medical records and successful visit at 5 years

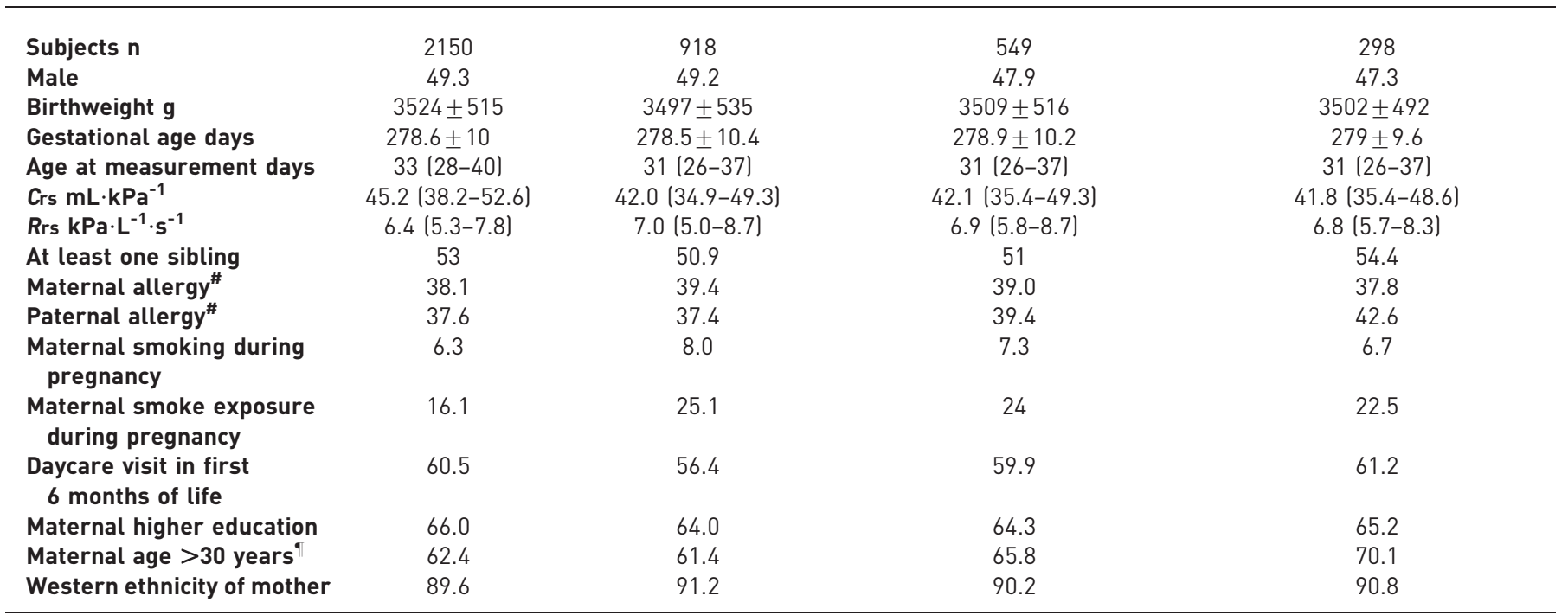

Data are presented as \%, mean \pm SD or median (interquartile range), unless otherwise stated. SOT: single occlusion technique; Crs: compliance of respiratory system; Rrs: resistance of respiratory system. " : allergy to pollen, house dustmite, food or pets; ": the only statistically significant difference between the subgroups of children already 5 years of age was between the mother's age being $>30$ years. p-values of the different subgroups compared with the total cohort are shown in table S1. 
Neonatal lung function and wheezing illnesses and asthma

Median (interquartile range) Crs was $42.1(35.4-49.3) \mathrm{mL} \cdot \mathrm{kPa}^{-1}$ and $R$ rs was $6.9(5.8-8.7) \mathrm{kPa} \cdot \mathrm{L}^{-1} \cdot \mathrm{s}^{-1}$. After adjustment for sex, weight, length and age at measurement, Crs was 41.6 (35.5-48.4) and Rrs was 6.4 (5.3-8.3). 38\% of all children had at least one consultation for wheezing illnesses during the first 3 years of life (range $0-18$ ) and $16 \%$ during the fourth to fifth years of life (range 0-8).

Tables 2 and 3 show the association between different lung function parameters and the number of consultations for wheezing illnesses during the two different periods. The incidence rate ratios of $\mathrm{Crs}$ were 0.86 and 0.73 , respectively, which meant that every $10 \mathrm{~mL} \cdot \mathrm{kPa}^{-1}$ increase in Crs was associated with a $14 \%$ reduction of consultations in the first 3 years of life and $27 \%$ in the fourth to fifth years of life. Every $\mathrm{kPa} \cdot \mathrm{L}^{-1} \cdot \mathrm{s}^{-1}$ increase in $R$ rs was associated with $10 \%$ more consultations in the first 3 years of life. In order to further examine the association between neonatal lung function and wheezing illnesses during the first 5 years of life, median values for $C r s$ and $R r s$ in children with different wheezing phenotypes were compared (table 4).

Children with persistent, but especially with a late-onset wheezing phenotype had lower neonatal Crs than children with other wheezing phenotypes. Although persistent wheezers seem to have higher neonatal Rrs, this was not significant.

Of all the children, $14.8 \%$ had asthma at the age of 5 years according to the definition based only on primary care consultations, prescriptions or referral for wheezing illnesses; $14.1 \%$ according to the definition based on patient reported symptoms and lung function at the age of 5 years. Tables 5 and 6 show the association between $C r$ and $R$ rs and asthma at the age of 5 years. A higher neonatal $C r$ is associated with a lower probability of having asthma, while no association was found between Rrs and asthma. The same results were found when other definitions for wheezing phenotypes and asthma were used (data not shown).

An increased neonatal Rrs was found to be associated with a significantly reduced FEV1 and FEF25-75\% at the age of 5 years (regression coefficient -0.009 per every $\mathrm{kPa} \cdot \mathrm{L}^{-1} \cdot \mathrm{s}^{-1}(95 \% \mathrm{CI}-0.014--0.001), \mathrm{p}=0.024$; regression coefficient -0.051 per every $\mathrm{kPa} \cdot \mathrm{L}^{-1} \cdot \mathrm{s}^{-1}$ (95\% CI $\left.-0.079--0.022\right), \mathrm{p}=0.001$, respectively), while an increased $C$ rs was associated with a significantly higher FEV1 and $\mathrm{FEF} 25-75 \%$ at the age of 5 years (regression coefficient 0.035 per every $10 \mathrm{~mL} \cdot \mathrm{kPa}^{-1}$ (95\% CI 0.019-0.052), $\mathrm{p}<0.001$; regression coefficient 0.061 per every $10 \mathrm{~mL} \cdot \mathrm{kPa}^{-1}(95 \%$ CI $0.001-0.122), \mathrm{p}=0.048$, respectively).

\section{Discussion}

This study shows that an increased neonatal Rrs is associated with more consultations for wheezing illnesses in the first 3 years of life, but not thereafter, while reduced neonatal $C$ rs is associated with more consultations until the age of 5 years, asthma at the age of 5 years and a late-onset or persistent wheezing phenotype. Adjustment for potential confounders did not influence the observed relationships.

To our knowledge, this is the first study to analyse the association between the SOT and wheezing illnesses during the first 5 years of life. We used a large birth cohort, with standardised lung function measurement and longitudinal, prospectively collected consultations for wheezing illnesses. The consultations and the

TABLE 2 Neonatal lung function parameters, compliance ( $\mathrm{Crs}$ ) and resistance (Rrs) of respiratory system, for children with a different number of consultations for wheezing illnesses

\begin{tabular}{|c|c|c|c|c|c|}
\hline & Subjects $\mathrm{n}$ & $\mathrm{Crs}^{\#} \mathrm{~mL} \cdot \mathrm{kPa}^{-1}$ & p-value & $\operatorname{Rrs}^{\#} \mathrm{kPa} \cdot \mathrm{L}^{-1} \cdot \mathrm{s}^{-1}$ & p-value \\
\hline $\begin{array}{l}\text { Consultations for wheezing illnesses } \\
\text { years } 1-3\end{array}$ & & & 0.192 & & 0.042 \\
\hline $1-2$ visits & 133 & $42.1(37.2-49.0)$ & & $6.4(5.1-8.3)$ & \\
\hline$>2$ visits & 78 & $40.6(33.9-48.0)$ & & $7.2(5.6-9.5)$ & \\
\hline $\begin{array}{l}\text { Consultations for wheezing illnesses } \\
\text { years } 4-5\end{array}$ & & & 0.010 & & 0.662 \\
\hline $1-2$ visits & 71 & $41.2(34.3-45.4)$ & & $6.6(5.5-8.6)$ & \\
\hline$>2$ visits & 19 & $35.7(32.8-40.1)$ & & $6.3(5.3-8.5)$ & \\
\hline
\end{tabular}

Data are presented as median (interquartile range), unless otherwise stated. \#: standardised according to sex, age, weight and length at measurement; ${ }^{\uparrow}$ : Kruskal-Wallis test. Values in bold indicate statistical significance. 
TABLE 3 Association between neonatal lung function parameters, compliance (Crs) and resistance (Rrs) of respiratory system, and consultations for wheezing illnesses

\begin{tabular}{|c|c|c|c|c|}
\hline \multirow[t]{2}{*}{ Risk factor } & \multicolumn{2}{|c|}{ Crude ${ }^{\#}$} & \multicolumn{2}{|c|}{ Adjusted } \\
\hline & IRR $(95 \%$ CI) & p-value & IRR $(95 \%$ CI) & p-value \\
\hline \multicolumn{5}{|c|}{ Primary care visits for wheezing illnesses in years $1-3$} \\
\hline Crs $\mathrm{mL} \cdot \mathrm{kPa}^{-1}$ per $10^{+}$ & $0.88(0.81-0.96)$ & 0.002 & $0.86(0.75-0.92)$ & $<0.001$ \\
\hline $\operatorname{Rrs~} \mathrm{kPa} \cdot \mathrm{L}^{-1} \cdot \mathrm{s}^{-1}$ & $1.07(1.03-1.10)$ & $<0.001$ & $1.10(1.06-1.14)$ & $<0.001$ \\
\hline \multicolumn{5}{|c|}{ Primary care visits for wheezing illnesses in years 4-5 } \\
\hline
\end{tabular}

IRR: incidence rate ratio. " : standardised according to sex, age, weight and length at measurement; ": adjusted for maternal smoke exposure during pregnancy, parental allergy, siblings, daycare visits during the first 6 months of life, maternal age at birth $>30$ years, maternal education and ethnicity of the mother; ${ }^{+}$: Crs is used per 10 , which means that a child with a Crs of $50 \mathrm{~mL} \cdot \mathrm{kPa}^{-1}$, for example, has 0.82 times more primary care visits for wheezing illness in years 1-3 compared with a child with a Crs of $40 \mathrm{~mL} \cdot \mathrm{kPa}^{-1}$. Values in bold indicate statistical significance.

lung function parameters were both analysed as continuous data using Poisson regression. However, there are some methodological considerations to be made.

First, the results are based on those children who had successful SOT tests and clinical data rather than either the whole cohort or those who also had lung function data at 5 years of age. Not all children had a successful SOT measurement and complete follow-up until the age of 5 years. Because the different subgroups of children that already reached the age of 5 years did not differ, except for the percentage of mothers aged $>30$ years, it is unlikely that this has introduced bias. Compared with the total cohort, the group of 5-year-olds was slightly younger at the time of SOT measurement, and their mothers were more often exposed to smoke during pregnancy. This could be the reason for the small difference in median lung function values. Crs and Rrs were adjusted for sex and age, weight and length at measurement and the multivariate regression analysis was also adjusted for smoke exposure.

Secondly, infants with smaller lungs might have lower Crs and more wheeze. We do not have lung volume data, but we measured thoracic circumference, which may reflect lung size. However, thoracic circumference appeared not to influence $C$ rs/Rrs values, while weight and length did [22]. Therefore, we do expect that the adjustment for size that we performed addresses this problem sufficiently.

Thirdly, primary care consultations for wheezing illnesses were used as outcome measure, by using the ICPC. Although in a previous article [21] we described that consultations are not only associated with severity of symptoms, the same results were found after adjustment for risk factors associated with consultations for respiratory illnesses. Although there is standardisation in primary care, as all general practitioners use ICPC, it is possible that different general practitioners classified wheezing illnesses in a different way. However, they were unaware of the SOT outcomes and, therefore, the possible misclassification is unrelated to SOT parameters and therefore will not have introduced bias.

Fourthly, in studies about asthma in children, several definitions of asthma and wheezing phenotypes are used [23]. To accomplish a large sample of newborns and a high participation rate, it was decided not to perform invasive tests in the WHISTLER project. Wheezing phenotypes and asthma had to be defined

TABLE 4 Median values for compliance (Crs) and resistance (Rrs) of respiratory system in children with different wheezing phenotypes, based on primary care consultations for wheezing illnesses and/or prescription of asthma medication ${ }^{\#}$

\begin{tabular}{|c|c|c|c|c|c|}
\hline & Subjects $\mathrm{n}$ & $\mathrm{Crs}^{\top} \mathrm{mL} \cdot \mathrm{kPa}^{-1}$ & p-value ${ }^{+}$ & $\operatorname{Rrs} \mathrm{kPa}^{\top} \mathrm{L}^{-1} \cdot \mathrm{s}^{-1}$ & p-value ${ }^{+}$ \\
\hline Nonwheezers & 340 & $41.9(35.8-48.7)$ & 0.040 & $6.4(5.3-8.1)$ & 0.139 \\
\hline Transient wheezers & 125 & $42.0(37.4-48.9)$ & & $6.4(5.5-8.3)$ & \\
\hline Persistent wheezers & 51 & $39.0(32.8-47.4)$ & & $7.5(5.4-9.1)$ & \\
\hline
\end{tabular}

Data are presented as median (interquartile range), unless otherwise stated. ${ }^{\#}$ : including oral or inhalation corticosteroids, inhalation $\beta$-agonists and/or leukotriene receptor antagonists; ": standardised according to sex, age, weight and length at measurement; ${ }^{+}$: Kruskal-Wallis test. 
TABLE 5 Neonatal lung function parameters, compliance (Crs) and resistance (Rrs) of respiratory system, for children with and without asthma

\begin{tabular}{|c|c|c|c|c|c|}
\hline & Subjects $n$ & $\mathrm{Crs}^{\#} \mathrm{~mL} \cdot \mathrm{kPa}^{-1}$ & p-value & $\operatorname{Rrs}^{\#} \mathrm{kPa} \cdot \mathrm{L}^{-1} \cdot \mathrm{s}^{-1}$ & p-value II $^{\text {t }}$ \\
\hline \multicolumn{6}{|c|}{ Asthma $^{+}$} \\
\hline \multicolumn{6}{|c|}{ Asthma $^{\mathbf{s}}$} \\
\hline No & 256 & $42.1(36.8-48.0)$ & 0.046 & $6.3(5.3-7.8)$ & 0.567 \\
\hline Yes & 42 & $39.0(30.5-45.7)$ & & $6.4(5.2-8.5)$ & \\
\hline
\end{tabular}

Data are presented as median (interquartile range), unless otherwise stated. ${ }^{\#}$ : standardised according to sex, age, weight and length at measurement; ${ }^{\top}$ : Mann-Whitney test; ${ }^{+}$: definition based only primary care consultations, prescriptions or referral for wheezing illnesses; §: definition also based on patient reported symptoms and lung function at the age of 5 years.

without specific immunoglobulin E values, or bronchial hyper-responsiveness tests. However, by using different definitions for wheezing phenotypes and asthma, the same results were found.

Lastly, we did not study the entire cohort. However, the WHISTLER project is an ongoing birth cohort, which began including participants in 2002. For this end-point, this is the final evaluation, and, within this group of children, significant results have been found. We have no reason to expect that with larger numbers the findings would alter.

We have demonstrated that an increased Rrs is associated with early wheezing illnesses and a reduced $C_{\mathrm{rs}}$ with wheezing illnesses during the first 5 years of life, but especially during the fourth to fifth years of life and asthma at the age of 5 years. Nonpersistence of the association between Rrs and consultations for wheezing illnesses suggests that this relationship is caused by lung characteristics that disappear over time. Several studies have suggested that the risk of early wheezing symptoms is most likely to be associated with reduced airway calibre, an outcome that is reflected by the Rrs. In the Tucson study [6], a transient wheezing phenotype was associated with lower neonatal maximal flow $\left(V^{\prime} \max \right)$ functional residual capacity (FRC) [6]. As both $V^{\prime}$ max FRC and Rrs reflect the diameter of the airways, one could expect the Rrs also to be associated with the transient wheezing phenotype. In our study, we did not find a significant association between the transient wheezing phenotype and a higher Rrs. One possible explanation could be that $V^{\prime}$ max FRC curves primarily reflect smaller airways while Rrs measured by SOT primarily reflects larger airways. It could also be caused by the fact that the symptoms had to be dichotomised, while especially the number of consultations seems to be associated with an increased Rrs. The Rrs seem to separate persistent wheezers from late-onset wheezers. While both these phenotypes were associated with a reduced $C r$ s, persistent wheezers also had an increased Rrs. A reduced $C r$ s was associated with increased consultations for wheezing illnesses in years $1-3$, but not with the transient wheeze phenotype. It is possible that this association is found because a reduced Crs is linked to persistent wheezers, who are also children with wheezing in years 1-3.

Our results confirm the results of HALAND et al. [9], that a reduced neonatal Crs is associated with childhood asthma. The Crs reflects the compliance of the total respiratory system, i.e. the compliance of the lung,

TABLE 6 Association between neonatal lung function, compliance ( $C r s$ ) and resistance (Rrs) of respiratory system, and asthma, defined in two different ways

\begin{tabular}{|c|c|c|c|}
\hline Risk factor & Subjects $n / N$ & OR $(95 \% \mathrm{Cl})$ & p-value \\
\hline Asthma\# & $81 / 549$ & & \\
\hline Crs $\mathrm{mL} \cdot \mathrm{kPa}^{-1}$ per $10^{\circ}$ & & $0.66(0.49-0.88)$ & 0.004 \\
\hline $\operatorname{Rrs~kPa} \cdot \mathrm{L}^{-1} \cdot \mathrm{s}^{-1}$ & & $0.99(0.88-1.12)$ & 0.874 \\
\hline Asthma $^{+}$ & $42 / 298$ & & \\
\hline Crs $\mathrm{mL} \cdot \mathrm{kPa}^{-1}$ per $10^{\circ}$ & & $0.60(0.40-0.89)$ & 0.011 \\
\hline $\operatorname{Rrs~} \mathrm{kPa} \cdot \mathrm{L}^{-1} \cdot \mathrm{s}^{-1}$ & & $1.01(0.86-1.19)$ & 0.905 \\
\hline
\end{tabular}

\#: definition based only primary care consultations, prescriptions and/or referral for wheezing illnesses; ': standardised according to sex, age, weight and length at measurement, and adjusted for maternal smoke exposure during pregnancy, parental allergy, siblings, daycare visits during the first 6 months of life, maternal age at birth $>30$ years, maternal education and ethnicity of the mother; ${ }^{+}$: definition also based on patient reported symptoms and lung function at the age of 5 years. 
thoracic cage, the bronchi and the alveoli. Although we do not completely understand the underlying pathophysiological mechanism, it would seem that a reduced neonatal Crs reflects underlying lung characteristics that are associated with wheezing symptoms and asthma during childhood. One could hypothesise that $C_{r s}$ and Rrs reflect different tissue properties or tissue localisation in the lung, which are differentially associated with wheezing phenotypes in later life.

There is increasing evidence that lung function "tracks" from birth into infancy and childhood, and from childhood into adulthood [6, 24-27]. In our study, a relationship between infant lung function and spirometry at 5 years of age was also found. An increased neonatal Rrs was found to be associated with a significantly reduced FEV 1 and $\mathrm{FEF}_{25-75 \%}$ at the age of 5 years, while an increased Crs was associated with a significantly higher FEV1 and $\mathrm{FEF} 25-75 \%$ at the age of 5 years.

Our study suggests that a reduced lung function is not only a consequence of the disease, but is also a cause of the disease. The Crs and Rrs seem to reflect different lung characteristics and are associated with symptoms in different age periods. Although these findings give insight into the underlying aetiopathology, the implications on an individual level are not so clear. There is a large overlap of Crs values and the difference is small; therefore, the lung function values could not be used as single predictors.

In conclusion, this study shows that an increased neonatal Rrs is associated only with wheezing illnesses during infancy, while a reduced neonatal $\mathrm{Crs}$ is associated with a late-onset or persistent wheezing phenotype and asthma in childhood.

\section{Acknowledgements}

The authors would like to thank all the parents and children who participated in the study, Rolien Bekkema and Liesbeth van der Feltz-Minkema (Dept of Paediatric Pulmonology, Wilhelmina Children's Hospital, University Medical Centre Utrecht, Utrecht, the Netherlands) for their assistance in recruiting the subjects and collecting the data, and Myriam Olling-de Kok (Dept of Paediatric Pulmonology, Wilhelmina Children's Hospital, University Medical Centre Utrecht) for her secretarial assistance.

\section{References}

1 Martinez FD, Morgan WJ, Wright AL, et al. Initial airway function is a risk factor for recurrent wheezing respiratory illnesses during the first three years of life. Group Health Medical Associates. Am Rev Respir Dis 1991; 143: 312-316.

2 Young S, Arnott J, O'Keeffe PT, et al. The association between early life lung function and wheezing during the first 2 yrs of life. Eur Respir J 2000; 15: 151-157.

3 Pike KC, Rose-Zerilli MJ, Osvald EC, et al. The relationship between infant lung function and the risk of wheeze in the preschool years. Pediatr Pulmonol 2011; 46: 75-82.

4 Dezateux C, Stocks J, Dundas I, et al. Impaired airway function and wheezing in infancy: the influence of maternal smoking and a genetic predisposition to asthma. Am J Respir Crit Care Med 1999; 159: 403-410.

5 Murray CS, Pipis SD, McArdle EC, et al. Lung function at one month of age as a risk factor for infant respiratory symptoms in a high risk population. Thorax 2002; 57: 388-392.

6 Martinez FD, Wright AL, Taussig LM, et al. Asthma and wheezing in the first six years of life. N Engl J Med 1995; 332: $133-138$.

7 Wilson NM, Lamprill JR, Mak JC, et al. Symptoms, lung function, and beta2-adrenoceptor polymorphisms in a birth cohort followed for 10 years. Pediatr Pulmonol 2004; 38: 75-81.

8 Turner SW, Palmer LJ, Rye PJ, et al. The relationship between infant airway function, childhood airway responsiveness, and asthma. Am J Respir Crit Care Med 2004; 169: 921-927.

9 Haland G, Carlsen KC, Sandvik L, et al. Reduced lung function at birth and the risk of asthma at 10 years of age. N Engl J Med 2006; 355: 1682-1689.

10 Kiley J, Smith R, Noel P. Asthma phenotypes. Curr Opin Pulm Med 2007; 13: 19-23.

11 Kurukulaaratchy RJ, Fenn M, Twiselton R, et al. The prevalence of asthma and wheezing illnesses amongst 10-yearold schoolchildren. Respir Med 2002; 96: 163-169.

12 Katier N, Uiterwaal CS, de Jong BM, et al. The Wheezing Illnesses Study Leidsche Rijn (WHISTLER): rationale and design. Eur J Epidemiol 2004; 19: 895-903.

13 Katier N, Uiterwaal CS, de Jong BM, et al. Feasibility and variability of neonatal and infant lung function measurement using the single occlusion technique. Chest 2005; 128: 1822-1829.

14 Gappa M, Colin AA, Goetz I, et al. Passive respiratory mechanics: the occlusion techniques. Eur Respir J 2001; 17: 141-148.

15 Mortola JP, Saetta M. Measurements of respiratory mechanics in the newborn: a simple approach. Pediatr Pulmonol 1987; 3: 123-130.

16 Frey U, Stocks J, Coates A, et al. Specifications for equipment used for infant pulmonary function testing. Eur Respir J 2000; 16: 731-740.

17 Beydon N, Davis SD, Lombardi E, et al. An official American Thoracic Society/European Respiratory Society statement: pulmonary function testing in preschool children. Am J Respir Crit Care Med 2007; 175: 1304-1345.

18 Verbeke M, Schrans D, Deroose S, et al. The International Classification of Primary Care (ICPC-2): an essential tool in the EPR of the GP. Stud Health Technol Inform 2006; 124: 809-814.

19 Koopman M, Zanen P, Kruitwagen CL, et al. Reference values for paediatric pulmonary function testing: the Utrecht dataset. Respir Med 2011; 105: 15-23.

20 Coxe S, West SG, Aiken LS. The analysis of count data: a gentle introduction to poisson regression and its alternatives. J Pers Assess 2009; 91: 121-136. 
21 de Jong BM, van der Ent CK, van Putte Katier N, et al. Determinants of health care utilization for respiratory symptoms in the first year of life. Med Care 2007; 45: 746-752.

22 Katier N, Uiterwaal CSPM, de Jong BM, et al. Passive respiratory mechanics measured during natural sleep in healthy term neonates and infants up to 8 weeks of life. Pediatr Pulmonol 2006; 41: 1058-1064.

23 Van Wonderen KE, Van Der Mark LB, Mohrs J, et al. Different definitions in childhood asthma: how dependable is the dependent variable? Eur Respir J 2010; 36: 48-56.

24 Stern DA, Morgan WJ, Wright AL, et al. Poor airway function in early infancy and lung function by age 22 years: a non-selective longitudinal cohort study. Lancet 2007; 370: 758-764.

25 Håland G, Carlsen KH, Devulapalli CS, et al. Lung function development in the first $2 \mathrm{yr}$ of life is independent of allergic diseases by 2 yr. Pediatr Allergy Immunol 2007; 18: 528-534.

26 Håland G, Lødrup Carlsen KC, Mowinckel P, et al. Lung function at $10 \mathrm{yr}$ is not impaired by early childhood lower respiratory tract infections. Pediatr Allergy Immunol 2009; 20: 254-260.

27 Phelan PD, Robertson CF, Olinsky A. The Melbourne Asthma Study: 1964-1999. J Allergy Clin Immunol 2002; 109: 189-194. 